\title{
Seismic Fragility Analysis of Multispan Reinforced Concrete Bridges Using Mainshock-Aftershock Sequences
}

\author{
Yutao Pang (iD) and Li Wu \\ Faculty of Engineering, China University of Geosciences, Lumo Road 388, Wuhan, Hubei, China \\ Correspondence should be addressed to Yutao Pang; pangyutaoyy@gmail.com
}

Received 22 May 2017; Accepted 11 March 2018; Published 11 April 2018

Academic Editor: Francesco Aymerich

Copyright (c) 2018 Yutao Pang and Li Wu. This is an open access article distributed under the Creative Commons Attribution License, which permits unrestricted use, distribution, and reproduction in any medium, provided the original work is properly cited.

\begin{abstract}
Although the knowledge and technology of performance-based earthquake engineering have rapidly advanced in the past several decades, current seismic design codes simply ignore the effect of aftershocks on the performance of structures. Thus, the present paper investigated the effect of aftershocks on seismic responses of multispan reinforced concrete (RC) bridges using the fragilitybased numerical approach. For that purpose, a continuous girder RC bridge class containing 8 bridges was selected based on the statistical analysis of the existing RC bridges in China. 75 recorded mainshock-aftershock seismic sequences from 10 well-known earthquakes were selected in this study. In order to account for the uncertainty of modeling parameters, uniform design method was applied as the sampling method for generating the samples for fragility analysis. Fragility curves were then developed using nonlinear time-history analysis in terms of the peak curvature of pier column and displacement of bearings. Finally, the system fragility curves were derived by implementing Monte Carlo simulation on multinormal distribution of two components. From the results of this investigation, it was found that, for the RC continuous bridges, the influence of aftershocks can be harmful to both bridge components and system, which increases both the component fragility of the displacement of bearings and seismic curvature of pier sections and system fragility.
\end{abstract}

\section{Introduction}

Previous well-known earthquake events (e.g., 1994 Northridge, 2008 Wenchuan, and 2012 Emilia) have shown that the mainshock of a large earthquake was followed by a large amount of aftershocks. This resulted from the complex process associated with the energy release and stress interaction between two large tectonic plates [1]. The largest aftershocks can cause complete damage or even collapse to structures and bridges which have already been damaged in the mainshock. This phenomenon was observed in the 2010$2011 \mathrm{M}_{\mathrm{w}} 7.4$ Christchurch and Canterbury earthquakes and the $2011 \mathrm{M}_{\mathrm{w}} 9.0$ Great East Japan earthquake [2,3]. The capacity of a mainshock-damaged structure would be insufficient to resist the strong aftershock, not only increasing the seismic risk of structural collapse but also causing the loss of life and economical property. Thus, it is important to conduct the vulnerability assessment of structures against mainshock and aftershocks. The results from vulnerability can provide valuable information to postearthquake management [4-6].

There are an increasing number of reported studies on the seismic responses and structural damage subjected to mainshock-aftershock (MS-AS) seismic sequences. Hatzigeorgiou and Beskos [7] repeated scaled mainshock records three times to generate MS-AS sequences and indicated that artificial seismic sequences would significantly increase the peak ductility demand. Goda [8] and Goda and Taylor [9] conducted probabilistic seismic analysis of inelastic SDOF systems with recorded sequences and artificial sequences based on empirical occurrence and scaling laws [10]. Their work indicates that seismic demand of SDOF systems was not significantly influenced by recorded seismic sequences, but for artificial sequences the effects of aftershock on seismic demand were found to be significant. Ruiz-García [11] provided a detailed investigation on seismic drift responses of frames using recorded far-fault and near-fault MS-AS 
sequences and showed that both recorded far-fault and nearfault aftershocks are not significant. From above studies, it can be seen that current methods of generating artificial MS-AS sequence may be conservative and not realistic, which are not suitable for structural damage assessment. For recorded seismic sequences, the numerical FE model used in these paper does not include the effect of structural damage accumulation which has turned out $[12,13]$ to be necessary for the simulation of seismic behavior. Thus, in this paper, the numerical simulation of RC bridge considers the modeling of seismic damage accumulation.

Seismic fragility is usually defined as the relationship between the damage probability and seismic parameters $[14,15]$. Nowadays, seismic fragility has become an important and critical step in the procedures of performance-based seismic evaluations. Li and Ellingwood [16] proposed a methodology to incorporate aftershock effect in PBEE framework for the structural damage assessment of steel frames. Yin and $\mathrm{Li}$ (2011) developed a complex methodology to estimate the loss after earthquakes and applied it to the wood frames. Luco et al. [17] proposed an incremental dynamic analysis (IDA) based numerical procedures to facilitate the probabilistic assessment for the increasing levels of damage states due to aftershocks. Ryu et al. [18] used the above procedures to generate the seismic fragility curves of reinforced concrete (RC) frames under repeated earthquake events. However, it should be noted that although the above studies have tackled the effects of aftershock in terms of seismic demands or fragility of specific structural models, the literatures are limited. More research should be warranted to evaluate the effects of aftershock using different structural types and models, especially for bridges which are the most important parts of entire transportation system.

For this purpose, the present paper employed the fragility method to study the effect of aftershocks on seismic demand of continuous girder multispan RC bridges. A typical continuous girder RC bridge class was selected. 75 real sequences from 10 well-known earthquakes were considered in this study. In order to account for the uncertainty of modeling parameters, uniform design method (UDM) was used for generating the samples. Both bridge component and system fragility curves were generated using nonlinear time-history analysis.

\section{Bridge System Characteristics and Uncertainty Treatment}

2.1. Description of Bridge Class and Structural Models. A common type highway bridge class of RC continuous girder bridges in China will be chosen as a case study. These bridges are designed according to the old Chinese bridge design specifications with limited longitudinal steel and widely spaced transverse ties. All bridges have three spans and twocolumn bents with sliding bearings constructed by PTEE sliding pads. Table 1 shows the selected eight representative individual bridges to represent the range of geometries. Figure 1 provides the schematic view of an example bridge. This bridge has three spans with same span length. The boxgirders, $3.0 \mathrm{~m}$ deep and $15.76 \mathrm{~m}$ wide, are adopted to construct
TABLE 1: Sample representative bridge geometries.

\begin{tabular}{lccc}
\hline Bridge number & Span length & Deck width & Column height \\
\hline$(1)$ & 39.6 & 16.25 & 14.14 \\
$(2)$ & 46.2 & 21.4 & 13.93 \\
$(3)$ & 38.9 & 14.55 & 16.21 \\
$(4)$ & 41 & 11.75 & 13.29 \\
$(5)$ & 42.6 & 15.76 & 19.80 \\
$(6)$ & 30.4 & 17.85 & 13.67 \\
$(7)$ & 34.5 & 12.45 & 14.48 \\
$(8)$ & 35.2 & 13.55 & 15.92 \\
\hline
\end{tabular}

the bridge deck. Bridge piers are $19.8 \mathrm{~m}$ long and have rectangle cross sections. Keeping all structural conditions the same, the present study developed other three-span bridges by changing the column height, deck width, and spans length.

Nonlinear time-history analyses of the bridge class were conducted in the open-source software OpenSees. Bridge girders and decks were modeled using elastic beam elements which were aligned along the central line of bridge decks because these components were rarely damaged in the seismic loading. A bilinear contact element was used to simulate the possible pounding behavior between the abutments and decks according to the recommendations of Muthukumar [19]. The bilinear materials were also adopted to model the bearings by setting suitable stiffness of the PTFE sliding pad and the sliding dowels. The nonlinear beam elements with 5 integrated points and around 300 discretized fiber sections were applied for the columns. Six linear translational and rotational springs were implemented to model the pile group foundations. Degrees of freedom with respect to the longitudinal translation (along the longitudinal axis of the bridge) and in-plane rotation at the abutment locations of bridge girders were allowed [20]. The degrees of freedom for vertical movement of bridge girders at abutment locations were fully constrained.

2.2. Modeling of Accumulated Damage. A typical RC column in as-built condition is most likely to fail due to the flexural compression of confined concrete under seismic loading [21]. However, considering the damage accumulation and the stiffness degradation of steel and concrete, the RC columns may fail because of the rupture of the longitudinal steel. Actually, a number of studies have been carried out on damage accumulation of RC bridge and low-cycle steel fatigue damage [22-26]. These studies have shown that it is critical to model the effect of low-cycle fatigue of steel and stiffness degradation of concrete in the models of columns.

The cyclic behavior and stiffness reduction of RC components can be modeled by many available material models in the OpenSees. The uniaxial concrete model Concrete02 proposed by Hoshikuma et al. (1997) could be applied to capture the degradation of concrete stiffness of both unconfined cover concrete and the confined core concrete. A multilinear hysteretic model, Hysteretic, is applied to model the longitudinal reinforcements, which are capable of capturing strength and stiffness degradation and pinching. 


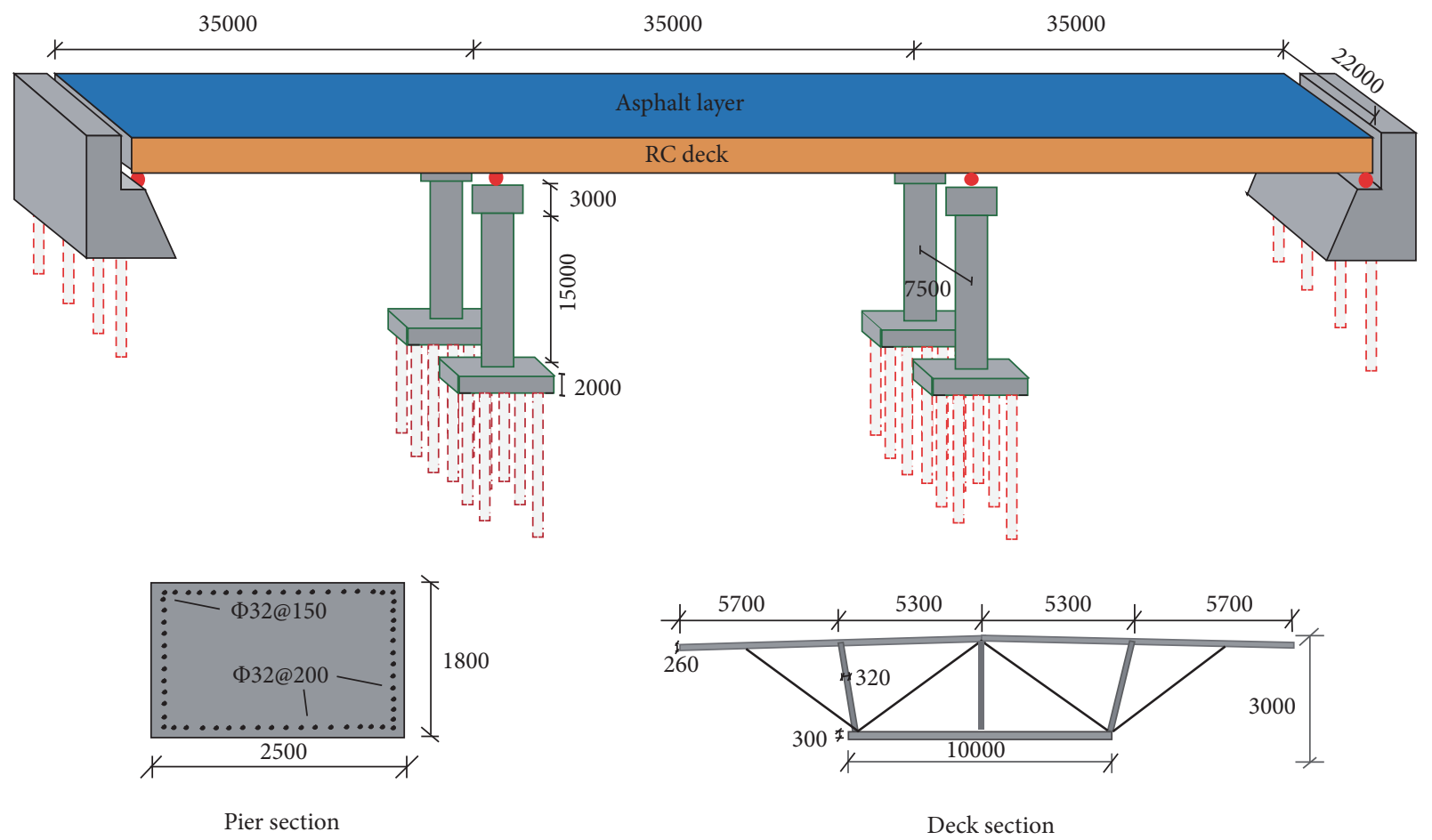

Figure 1: Layout of the example RC bridges.

TABLE 2: Variable modeling parameters with upper and lower levels in the study.

\begin{tabular}{|c|c|c|c|c|c|}
\hline Modeling parameters & Units & Distribution & Lower & Median & Upper \\
\hline Bearing stiffness & - & Lognormal & 0.09 & 0.2 & 0.48 \\
\hline Coefficient of friction & - & Uniform & 0.55 & 1 & 1.45 \\
\hline Damping ratio & - & Normal & 0.03 & 0.04 & 0.05 \\
\hline Deck-abutment gap & $\mathrm{mm}$ & Normal & 101.6 & 128.2 & 155.8 \\
\hline Steel yield strength & $\mathrm{MPa}$ & Lognormal & 405 & 435 & 510 \\
\hline Steel stiffness & $\mathrm{MPa}$ & Lognormal & $1.4 e 5$ & $2.0 e 5$ & $2.8 e 5$ \\
\hline Concrete yield strength & $\mathrm{MPa}$ & Lognormal & 26.6 & 38.3 & 47.9 \\
\hline Concrete ultimate strength & $\mathrm{MPa}$ & Lognormal & 16.1 & 26.73 & 37.4 \\
\hline
\end{tabular}

The strength and stiffness degradation of the longitudinal reinforcements are captured by using two parameters in the Hysteretic model, namely, Damagel and Damage2. While Damage1 affects the ductility degradation, Damage2 captures the degradation of energy dissipation. Both parameters have significant influence on the strength and stiffness degradation $[24,25]$. In order to consider the low-cycle fatigue effect, a fatigue material model, Fatigue [27], is attached to the Hysteretic model in the OpenSees.

2.3. Structural Parameter Uncertainty. While uncertainty of ground motions is a key source of uncertainty influencing the fragility curves of bridge components, the ranges of structural model parameters must also be included in the seismic fragility analysis (Pang et al. 2014a). The uncertainty of structural model parameters is not only due to the inherent variability in material properties, but also attributed to the incomplete data or modeling assumptions because of the lack of knowledge. Many modeling parameters associated with material properties and geometric uncertainties, such as yield strength of steel, initial stiffness of bearings, or gaps at the deck-abutment expansion joint, should be also considered as random variables. Thus, 8 modeling parameters of bridge model are considered as random variables in Table 2 . These modeling parameters are selected based on past findings [28] due to their significant effect on seismic demands. The coefficient of friction and initial stiffness of the bearings which define hysteretic response of the bearings are also considered as variability. The probability density functions (PDFs) applied for the modeling parameters reflect the upper and lower bounds and frequency based on an actual survey of regional bridge, past test data, and related literature [28]. Table 2 also presents different PDFs (normal, lognormal, or uniform) for 8 structural modeling parameters.

2.4. Fragility Methodology. The component fragility curves present the exceeding probability of bridge components at four damage states (slight, moderate, extensive, or complete) 
TABLE 3: Capacity estimates for pier and bearing components.

\begin{tabular}{lccccccc}
\hline \multirow{2}{*}{ Component } & \multicolumn{2}{c}{ Slight } & \multicolumn{2}{c}{ Moderate } & \multicolumn{2}{c}{ Extensive } & \multicolumn{2}{c}{ Complete } \\
& $\mu_{c}$ & $\sigma_{c}$ & $\mu_{c}$ & $\sigma_{c}$ & $\mu_{c}$ & $\sigma_{c}$ & $\mu_{c}$ \\
\hline Reinforced concrete pier & 1.4 & 0.45 & 2.5 & 0.47 & 3.7 & 0.66 & 5.85 \\
Bearing (displacement) $(\mathrm{mm})$ & 20 & 0.51 & 100 & 0.68 & 150 & 0.76 & 200 \\
\hline
\end{tabular}

when subjected to the seismic loadings, which can be used to capture the major failure modes of bridges. Thus, this study aimed to generate the fragility curves of two major components of bridges, namely, columns and sliding bearings. The detailed information of fragility methodology was illustrated in the following paragraphs.

In the fragility methodology, the modeling parameters were first defined as random variables and then sampled based on the uniform design method [29] to generate various numerical models of the considered bridge class. The study by Pang et al. [29] has shown that the ground motion uncertainty has a significant effect on the fragility curves. Thus, in this paper, a suite of 75 recorded ground motions was used in the nonlinear time-history analysis. The peak ground acceleration (PGA) of 75 mainshock ground motions ranges from $0.02 \mathrm{~g}$ to $1.95 \mathrm{~g}$. The PGA of 75 aftershock ground motions ranges from $0.02 \mathrm{~g}$ to $1.43 \mathrm{~g}$. Seismic responses of two major components from both mainshock and MS-AS sequences were monitored throughout the nonlinear timehistory analysis. Then, the power law proposed by Cornell et al. [14] was applied to conduct the regression analysis in order to develop the probabilistic seismic demand models (PSDMs) of two major components. The PSDM reflected the relationship between the peak responses of various components and the ground motion intensity measure (IM). In this paper, the peak ground acceleration (PGA) instead of spectral acceleration at fundamental period was used to generate the fragility curves of various components because the PGA information for a given bridge site was readily accessible to bridge engineers. In fact, a recent study by Padgett et al. [30] has shown that the PGA can be considered an optimal IM in fragility analysis from efficiency, practicality, proficiency, sufficiency, and hazard computability considerations.

The developed PSDMs as well as the component capacities can be used to estimate the exceeding probability of components based on the lognormal distributions, which was conditioned upon PGA. It should be noted that the PGA for MS-AS sequences is the max acceleration value of MSAS sequences. The median value of peak responses, $\mu_{D}$, and dispersion, $\sigma_{\ln D}$, are obtained through regression analysis in terms of the following form:

$$
\begin{aligned}
\mu_{D} & =a \mathrm{IM}^{b} \\
\text { or } \ln \left(\mu_{D}\right) & =\ln a+b \ln (\mathrm{IM}) \\
\sigma_{\ln D} & =\sqrt{\frac{\sum_{i=1}^{n}\left[\ln \left(\mathrm{EDP}_{i}\right)-\left(\ln a+b \ln \mathrm{IM}_{i}\right)\right]^{2}}{n-2}},
\end{aligned}
$$

where the parameters $a$ and $b$ are regression coefficients obtained from the response data of nonlinear time-history analyses; the parameter $n$ is the number of the nonlinear time-history analyses.

The fragility probability of each component was obtained by comparing the PSDMs and component capacities, $C$. Thus, the component capacities should be carefully defined, which should be based on the damage levels or functionality inhibition of components at different damage states. The component capacities in this paper (Table 3) for columns and sliding bearings were defined based on the bearing displacement and column curvature for the continuous girder RC bridges. Four damage states, slight, moderate, extensive, and complete, were used for the description of component capacities.

It was assumed that both the demand and capacity were modeled by lognormal distributions. Thus, the component fragility curves were in terms of the following closed form $[14,28]$ :

$$
\operatorname{Pr}=\Phi\left[\frac{\ln \left(\mu_{D} / \mu_{C}\right)}{\sqrt{\sigma_{\ln D}^{2}+\sigma_{\ln C}^{2}}}\right]=\Phi\left[\frac{\ln (\mathrm{IM})-\ln (\mathrm{med})}{\xi}\right]
$$

where med is the fragility median (PGA) and $\xi$ is the fragility dispersion or logarithmic standard deviation. Additionally, $\ln ($ med $)=\left[\ln \left(\mu_{C}\right)-\ln (a)\right] / b ; \xi=\sqrt{\sigma_{\ln D}^{2}+\sigma_{\ln C}^{2}}$

The estimate of system level fragility is accomplished by the implementation of the so-called joint PSDM method proposed by Nielson and DesRoches [28]. In this joint PSDM method, the correlation coefficients between the selected components are estimated firstly based on the peak responses from different ground motions. Then these correlation coefficients are used to generate the covariance matrix, which can be used to form the conditional joint normal distribution of various components, known as the joint PSDM. Finally, the Monte Carlo method is applied to both joint PSDM and capacity models to generate the random vectors. These vectors contain random numbers of capacity and demands for various components. When peak response of one component exceeds a specific capacity, the system is determined as failure. Thus, the random vectors can be used to calculate the system probability of bridges.

\section{Ground Motion Data for Mainshock-Aftershock Sequences}

In order to investigate the effect of the aftershocks on highway bridges, the selected earthquakes need to include at least one aftershock, which can be used to form the seismic sequence. In this study, the considered earthquakes were chosen based on the following criteria: (a) magnitude of major aftershock > 

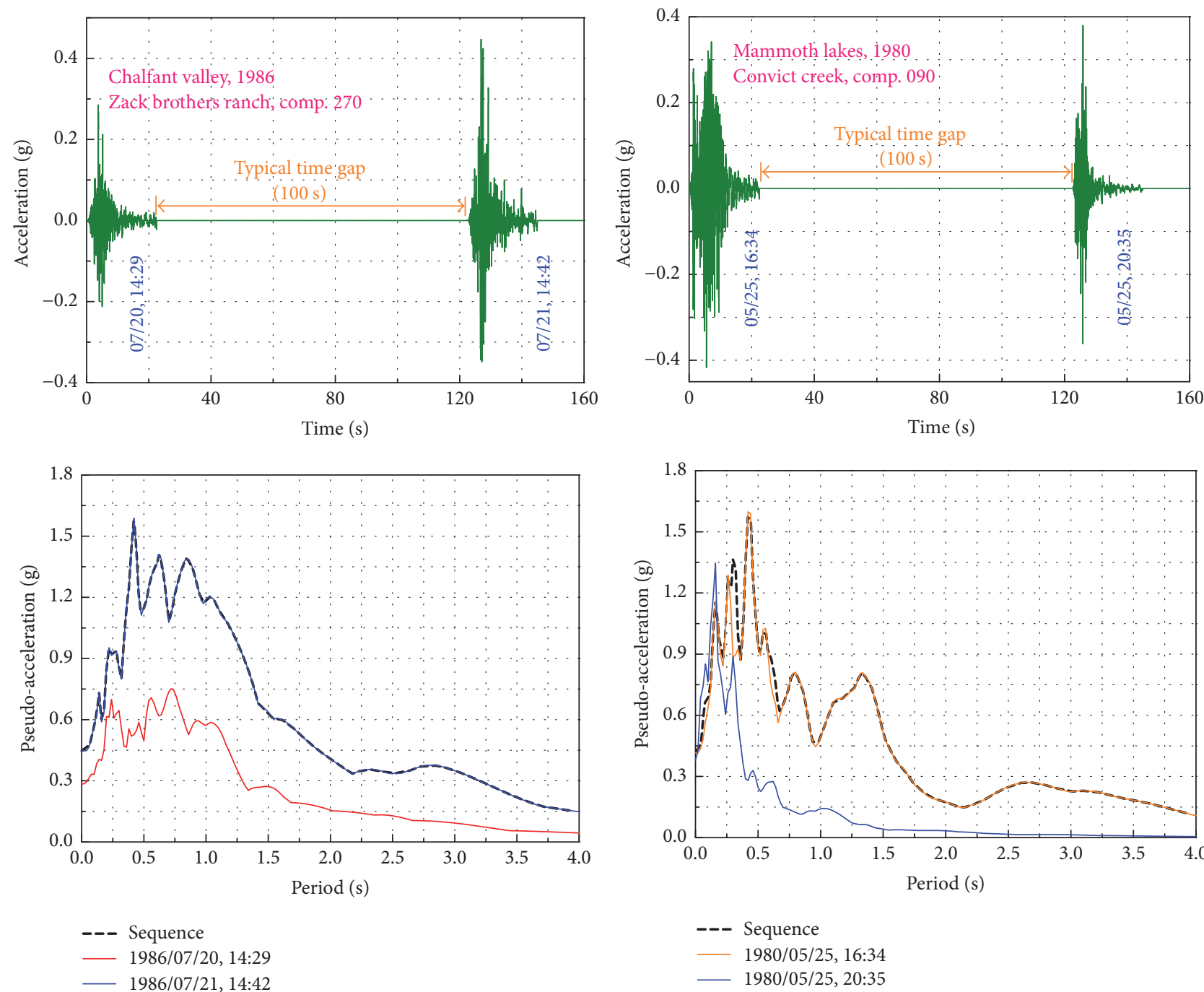

FIGURE 2: Examples of mainshock-aftershock seismic sequences and corresponding elastic spectra with 5\% damping ratio.

4.0 to avoid minor ground motions; (b) the recorded station far away from the city to represent the free field motions; (c) the PGA of aftershock close to the PGA of mainshock (the ratio > 0.7); (d) the Vs30 ranging from 300 to $600 \mathrm{~m} / \mathrm{s}$ to represent the subsoil conditions of the bridge considered; (e) aftershock happening within three months after mainshock; (f) both mainshock and aftershock recorded in the same direction and station. Using the above criteria, 10 well-known earthquakes were selected from the COSMOS and PEER ground motion databases, containing 75 recorded seismic sequences listed in Table 4.

In order to cease the vibration caused by mainshock, the $100 \mathrm{~s}$ gap with zero acceleration was used to separate the mainshock and aftershock in the development of seismic sequences. It was also verified by the recorded time-history responses of various components that $100 \mathrm{~s}$ was enough to cease the moving of every component when damping ratio was $5 \%$. Figure 2 shows two selected seismic sequences and corresponding elastic spectra with $5 \%$ damping ratio. It can be seen clearly from Figure 2 that the PGA of aftershock may be larger than the PGA of the mainshock in some seismic sequences, although the magnitude of aftershock is lower than that of mainshock. Figure 3 shows the individual and median pseudo-acceleration elastic spectra (damping ratio 5\%). As shown in Figure 3, the median pseudo-acceleration elastic spectra of seismic sequences are larger than that of mainshock.

\section{Demand and Capacity Estimates}

The nonlinear time-history analyses were conducted for both mainshock and MS-AS seismic sequences. The peak responses were then recorded to construct the PSDMs of various components. In the PSDMs, PGA was used to relate the peak responses with IM. Figure 4 illustrated the PSDMs for pier curvature (the ratio of curvature to yield curvature) and bearing displacement for the bridges. In Figure 4, the regression lines for both mainshock and MSAS seismic sequences were plotted in order to show the difference between them. As shown in Figure 4, both the 
TABLE 4: List of 75 recorded mainshock-aftershock seismic sequences.

\begin{tabular}{|c|c|c|c|c|}
\hline Number & Earthquake & Station location and number & Mainshock-PGA (g) & Aftershock-PGA (g) \\
\hline (1) & Chi-Chi, Taiwan & $024-\mathrm{E}$ & 0.28 & 0.19 \\
\hline (2) & Chi-Chi, Taiwan & $024-\mathrm{N}$ & 0.17 & 0.09 \\
\hline (3) & Chi-Chi, Taiwan & 035-E & 0.25 & 0.13 \\
\hline (4) & Chi-Chi, Taiwan & $035-\mathrm{N}$ & 0.25 & 0.12 \\
\hline (5) & Coalinga & $\mathrm{CO}-045$ & 0.60 & 0.10 \\
\hline (6) & Coalinga & $\mathrm{CO}-135$ & 0.53 & 0.21 \\
\hline (7) & Chalfant Valley & Zack Bros. Ranch 270 & 0.27 & 0.44 \\
\hline (8) & Chalfant Valley & Zack Bros. Ranch 360 & 0.23 & 0.39 \\
\hline (9) & Chalfant Valley & CV $424-70$ & 0.17 & 0.03 \\
\hline (10) & Chalfant Valley & CV424-160 & 0.14 & 0.07 \\
\hline (11) & Chalfant Valley & CV428-270 & 0.29 & 0.16 \\
\hline (12) & Chalfant Valley & CV428-360 & 0.39 & 0.10 \\
\hline (13) & Imperial Valley & IP-225 & 0.28 & 0.10 \\
\hline (14) & Imperial Valley & IP-262 & 0.24 & 0.06 \\
\hline (15) & Imperial Valley & IP-315 & 0.20 & 0.07 \\
\hline (16) & Imperial Valley & IP-1140 & 0.14 & 0.06 \\
\hline (17) & Imperial Valley & IP-1230 & 0.14 & 0.03 \\
\hline (18) & Imperial Valley & IP-3230 & 0.22 & 0.10 \\
\hline (19) & Imperial Valley & IP-11140 & 0.37 & 0.10 \\
\hline (20) & Imperial Valley & IP-11230 & 0.38 & 0.19 \\
\hline (21) & Japan & FKS005 E-W & 0.45 & 0.24 \\
\hline (22) & Japan & FKS005 N-S & 0.74 & 0.31 \\
\hline (23) & Japan & IWT007 E-W & 0.70 & 0.75 \\
\hline$(24)$ & Japan & IWT007 N-S & 0.63 & 0.36 \\
\hline (25) & Japan & IWT009 E-W & 0.51 & 0.67 \\
\hline (26) & Japan & IWT009 N-S & 0.58 & 0.59 \\
\hline (27) & Japan & MYG003 E-W & 0.75 & 0.77 \\
\hline (28) & Japan & MYG003 N-S & 0.54 & 0.63 \\
\hline (29) & Japan & MYG012 E-W & 1.95 & 1.43 \\
\hline (30) & Japan & MYG012 N-S & 0.81 & 0.61 \\
\hline (31) & Japan & MYG013 E-W & 0.99 & 1.00 \\
\hline (32) & Japan & MYG013 N-S & 1.52 & 0.59 \\
\hline (33) & Livermore & ANTIOCH-270 & 0.04 & 0.11 \\
\hline (34) & Livermore & ANTIOCH-360 & 0.02 & 0.05 \\
\hline (35) & Livermore & CHAN1 & 0.24 & 0.47 \\
\hline$(36)$ & Livermore & CHAN2 & 0.23 & 0.35 \\
\hline (37) & Livermore & CHAN3 & 0.15 & 0.15 \\
\hline (38) & Livermore & CHAN4 & 0.15 & 0.27 \\
\hline (39) & Livermore & CHAN6 & 0.06 & 0.08 \\
\hline$(40)$ & Livermore & DVD156 & 0.13 & 0.04 \\
\hline$(41)$ & Livermore & DVD246 & 0.26 & 0.04 \\
\hline$(42)$ & Livermore & KOD180 & 0.15 & 0.28 \\
\hline (43) & Livermore & KOD270 & 0.06 & 0.08 \\
\hline (44) & Livermore & SRM070 & 0.06 & 0.05 \\
\hline$(45)$ & Livermore & SRM340 & 0.04 & 0.05 \\
\hline$(46)$ & Mammoth Lakes & Convict Creek 90 & 0.4 & 0.34 \\
\hline (47) & Mammoth Lakes & Convict Creek 180 & 0.39 & 0.49 \\
\hline$(48)$ & Mammoth Lakes & LUL245 & 0.27 & 0.07 \\
\hline (49) & Mammoth Lakes & LUL250 & 0.27 & 0.41 \\
\hline$(50)$ & Mammoth Lakes & LVD090 & 0.06 & 0.04 \\
\hline
\end{tabular}


TABLE 4: Continued.

\begin{tabular}{|c|c|c|c|c|}
\hline Number & Earthquake & Station location and number & Mainshock-PGA (g) & Aftershock-PGA (g) \\
\hline$(51)$ & Mammoth Lakes & LVL090 & 0.08 & 0.06 \\
\hline (52) & Northridge & ELL090 & 0.15 & 0.02 \\
\hline (53) & Northridge & ELL180 & 0.11 & 0.02 \\
\hline (54) & Northridge & GLE170 & 0.13 & 0.07 \\
\hline (55) & Northridge & GLE260 & 0.16 & 0.07 \\
\hline (56) & Northridge & MRP090 & 0.19 & 0.14 \\
\hline (57) & Northridge & MRP180 & 0.29 & 0.18 \\
\hline (58) & Northridge & ORR090 & 0.57 & 0.14 \\
\hline (59) & Northridge & ORR360 & 0.51 & 0.12 \\
\hline$(60)$ & Northridge & RO3000 & 0.28 & 0.14 \\
\hline (61) & Northridge & RO3090 & 0.45 & 0.10 \\
\hline (62) & Northridge & TUJ262 & 0.17 & 0.11 \\
\hline (63) & Northridge & TUJ352 & 0.25 & 0.10 \\
\hline (64) & Petrolia & PE156-90 & 0.65 & 0.43 \\
\hline (65) & Petrolia & PE156-360 & 0.58 & 0.59 \\
\hline (66) & Petrolia & PE509-90 & 0.17 & 0.05 \\
\hline (67) & Petrolia & PE509-360 & 0.15 & 0.07 \\
\hline (68) & Petrolia & PE530-90 & 0.17 & 0.48 \\
\hline (69) & Petrolia & PE530-360 & 0.22 & 0.28 \\
\hline (70) & Whittier Narrows & BIR090 & 0.23 & 0.16 \\
\hline (71) & Whittier Narrows & BIR180 & 0.35 & 0.13 \\
\hline (72) & Whittier Narrows & DWN180 & 0.20 & 0.06 \\
\hline (73) & Whittier Narrows & DWN270 & 0.16 & 0.06 \\
\hline (74) & Whittier Narrows & MTW000 & 0.12 & 0.15 \\
\hline (75) & Whittier Narrows & MTW090 & 0.18 & 0.16 \\
\hline
\end{tabular}

bearing displacement and pier curvature were increasing for ground shaking of MS-AS sequence. This can be explained by the large value of the median pseudo-acceleration elastic spectra of MS-AS sequence. It could be found in another study [18] that the MS-AS sequences increased the seismic responses of RC frames. Moreover, Figure 4 indicated that the aftershocks not only increased the median (see (1)) of the seismic demands, but also affected the dispersion (see (2)). The MS-AS sequences slightly reduced the dispersion of bearing displacement from 1.31 to 1.2 and pier curvature from 0.47 and 0.45 . In order to construct the JPSDM for system evaluation, correlation coefficients were estimated for different component demands using peak responses.

Four damage states, namely, slight, moderate, extensive, and complete damage, were considered in the present paper. The capacities for each component under these four damage states should be estimated considering the consistency of the entire bridge system. The consistency was usually defined as similar impact caused by the damage of different components under one specific damage state on the functional performance of the bridge. In this paper, the construction procedures described in the study [31] were applied for capacity estimates. Table 3 provided the estimation of seismic capacity of bearing displacement and pier curvature for the case study continuous girder bridges.

\section{Components and System Fragility Curves}

The component and system fragility curves of bridges under mainshock and MS-AS sequences provided useful information on the influence of aftershocks. The component fragilities can be generated using (3). Figure 5 illustrated the fragility curves of bearing displacement at four considered damage states under mainshock and MS-AS sequences. The component fragilities for the bridge under MS-AS sequences (solid line) are shown relative to the bridges under mainshock ground motions (dash line). It should be noted in Figure 5 that the PGA for solid line is calculated from MSAS sequences, while the PGA for dash line is calculated from mainshock records. For these four damage states, it is shown that the influence of aftershocks on fragility curves of bearing displacement increases the bearing vulnerability, while the aftershock has similar effect at different levels of damage states.

Similarly, Figure 6 illustrated the fragility curves of column curvature at four damage states under mainshock and MS-AS sequences. From Figure 6, it is shown that the aftershocks essentially increase the vulnerability of bridge piers, while increasing with the levels of damage states. For example, the aftershock slightly increases the column fragility at the slight damage state while it considerably increases the column fragility at the moderate and extensive damage states. 


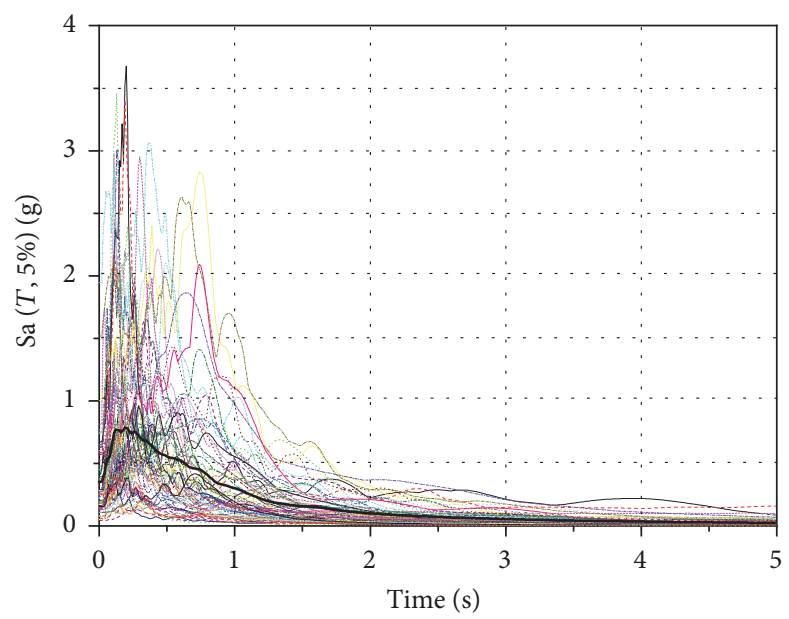

Mainshock-aftershock sequence

Median curve

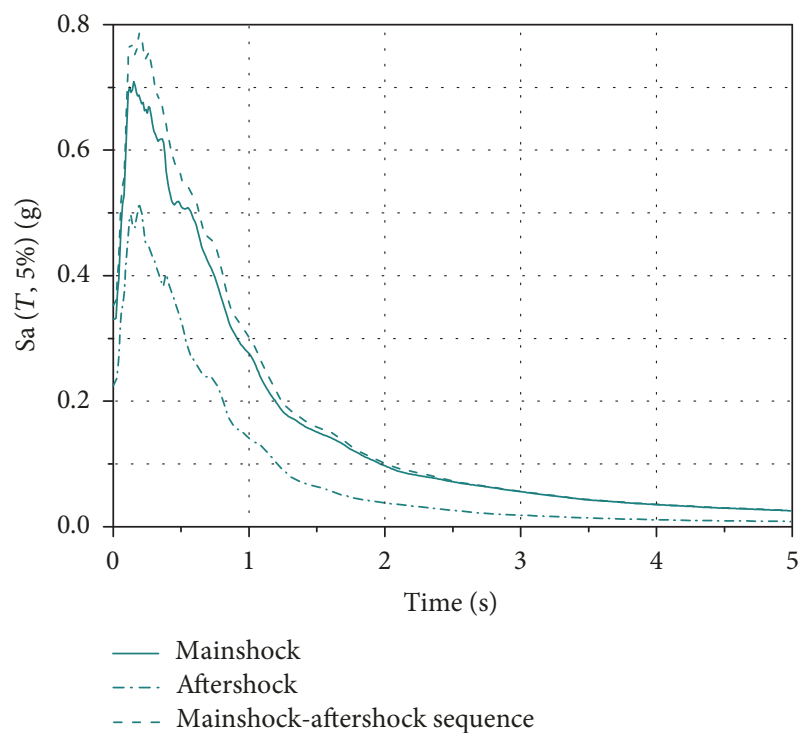

(b)

FIGURE 3: Pseudo-acceleration elastic spectra: (a) individual seismic sequences and (b) median values (damping ratio 5\%).

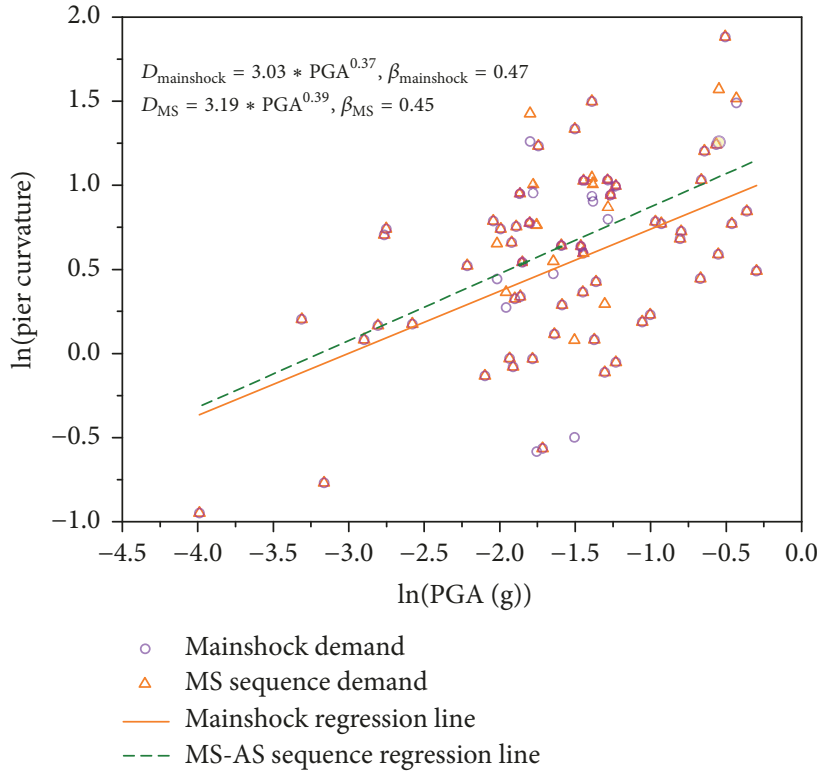

(a)

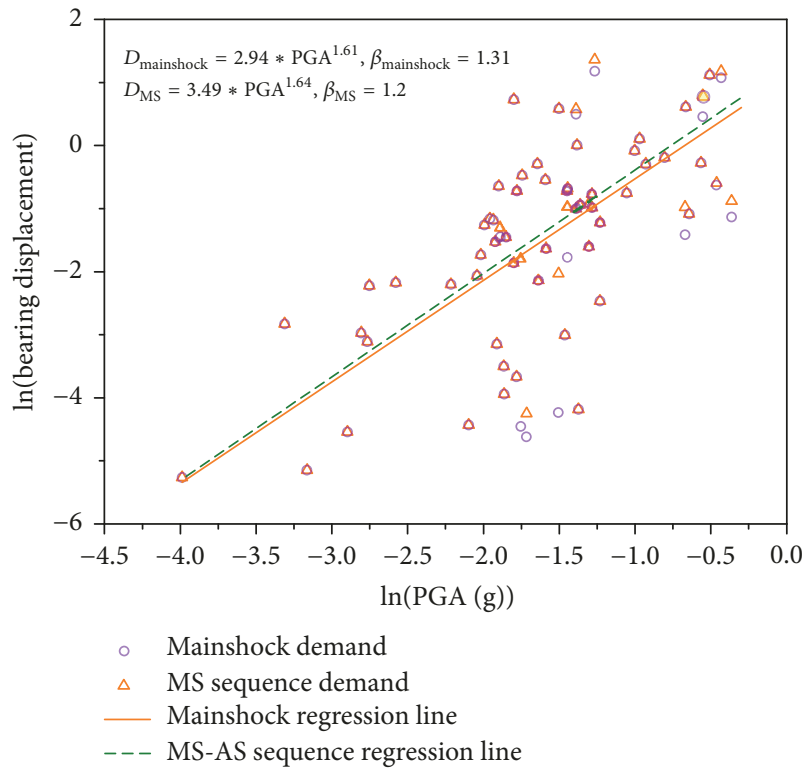

(b)

FIGURE 4: Comparison of the PSDMs for selected bridge class under mainshock and MS-AS sequences.

This may be because after the slight or moderate damage state, the increase of seismic intensity can greatly increase section curvature.

The bridge system contains many critical components. Each component would contribute the vulnerability of entire system. Thus, it is difficult to say that single component can be used as an ideal candidate for the bridge system assessment. From Figures 5 and 6 , it can be found that the fragility probabilities of both bearing and pier at four damage states are large. No one can simply neglect one component and claim that it has no effect on the vulnerability of bridge system. For the bridge class considered in this study, the contributions of both bearing and bridge pier were considered to estimate the system fragilities of bridges. The system fragilities were developed using the so-called joint PSDM method. In this method, the correlation coefficients were estimated as 0.005 for bearing displacement and pier curvature. Then, this correlation coefficient was used to build the joint normal distribution. The Monte Carlo simulation was finally applied to calculate the exceeding probability of bridge system. The system fragility curves of the considered bridge class at slight, moderate, extensive, and complete 


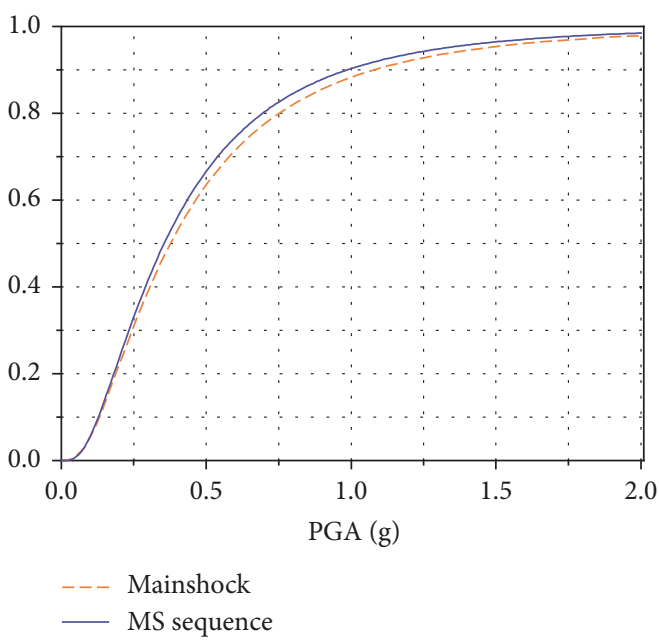

(a)

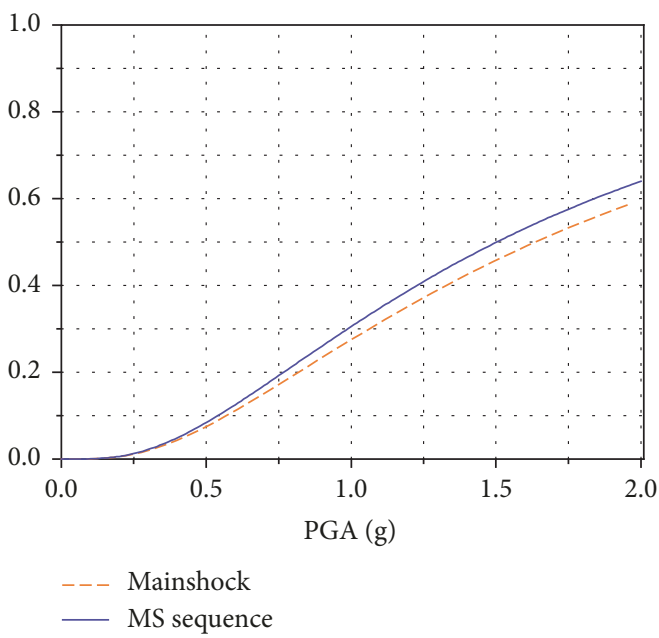

(c)

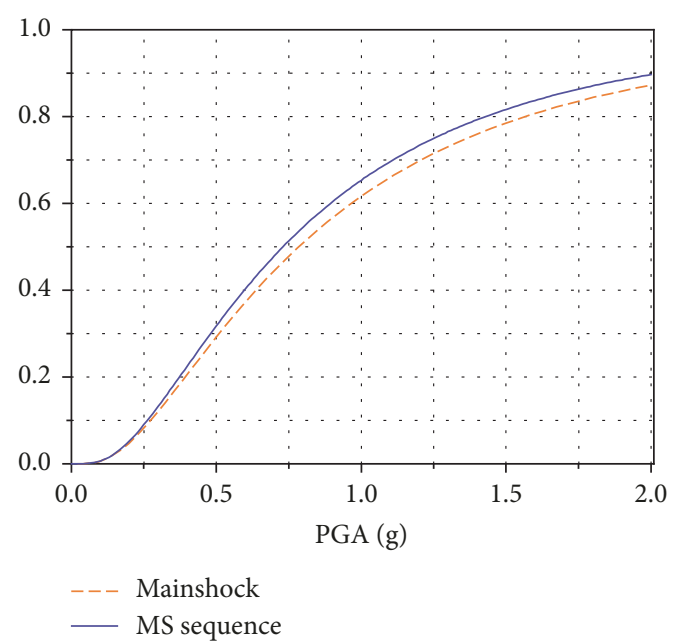

(b)

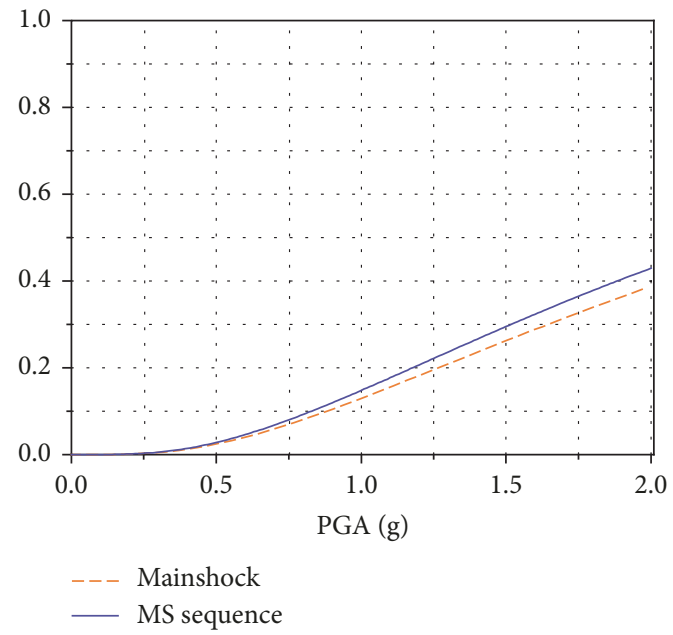

(d)

FIGURE 5: Fragility curves of bearing displacement at four damage states under mainshock and MS-AS sequences: (a) slight; (b) moderate; (c) extensive; (d) complete.

damage states under mainshock ground motions and MS-AS sequences are shown in Figure 7. It should be also noted in Figure 7 that the PGA for solid line is calculated from MSAS sequences, while the PGA for dash line is calculated from mainshock ground motions.

From Figure 7, it is evident that the influence of aftershocks appears to be harmful to bridge system at four considered damage states, which increase the damage probability conditional on a specific PGA. Similarly, the influence of aftershock on bridge system changes with the damage states. For example, the aftershocks slightly increase the system vulnerability at the slight damage state, while increasing the influence of the system vulnerability at the moderate and extensive damage states. Again, the change of the lower and upper bound fragility has the same trend as that of the system fragility. No matter the changes, the system fragility is always more fragile than the components and located between the lower and upper bound lines. In order to show the difference of system fragilities using mainshock and MS-AS sequences, the median fragility is calculated in terms of PGA. It should be noted that a smaller median fragility indicates a larger vulnerability. Figure 8 shows the median fragility at four damage states.

From Figure 8, it can be seen that the system vulnerability is improved by $16.7 \%$ while the vulnerability of bridge is improved by $52.5 \%$ at extensive damage state. Thus, if one only uses the bridge pier to assess the effect of aftershock, larger influence $(52.5 \%)$ can be obtained when comparing to actual system fragility (16.7\%). Similar trends can be also seen in the other damage states. So it is important to evaluate the vulnerability of bridge system, rather than only assess the effect of aftershock based on a single component.

\section{Summary and Conclusions}

The paper has proposed an analytical methodology to generate the components and system fragility curves of continuous girder RC bridge classes under mainshock-aftershock seismic 


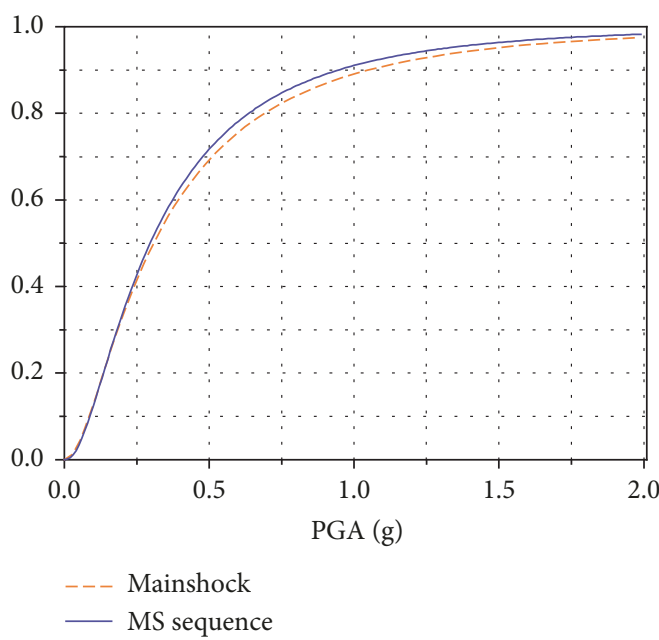

(a)

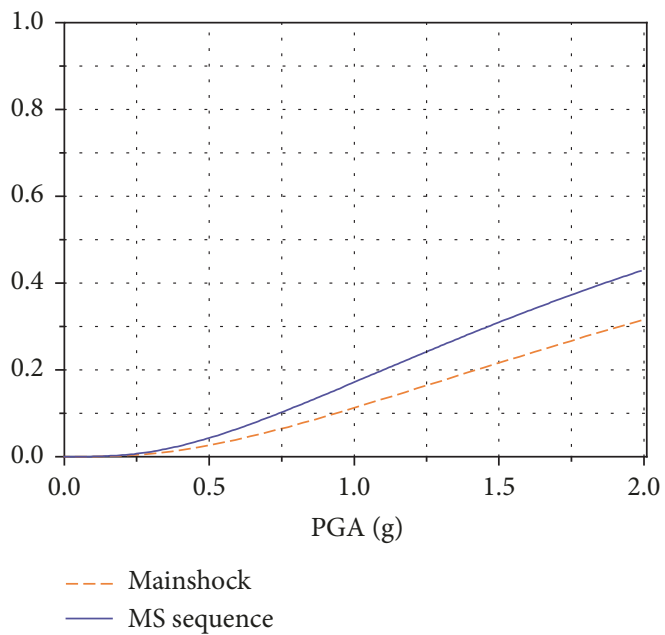

(c)

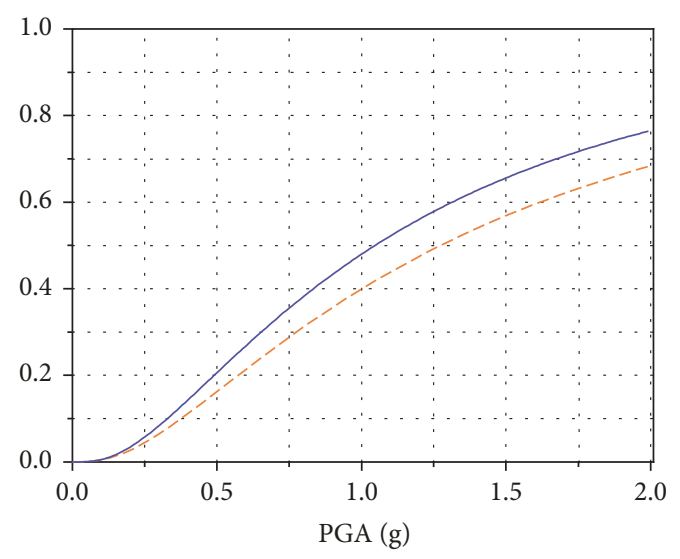

Mainshock

— MS sequence

(b)

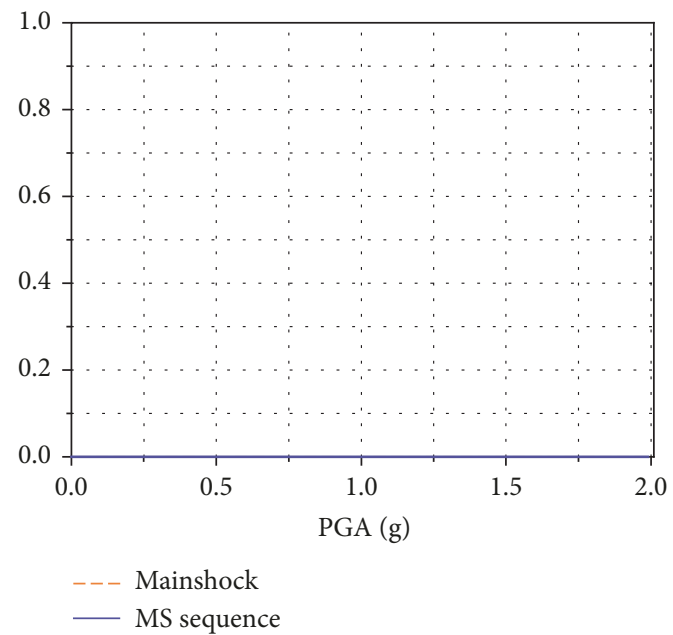

(d)

FIGURE 6: Fragility curves of column curvature at four damage states under mainshock and MS-AS sequences: (a) slight; (b) moderate; (c) extensive; (d) complete.

sequences. The aim is to investigate the effect of aftershock on seismic performance of bridges when assessing both component and system fragility. A continuous girder RC bridge class containing 8 bridges is selected. 3D finite element models are then developed accounting for the uncertainty of modeling parameters and analyzed using the selected 75 recorded mainshock-aftershock seismic sequences. The PSDMs are built for bearing displacement and pier curvature. The effect of aftershock on seismic demands of bridge is illustrated by comparing the regression line in the PSDMs. The component fragility curves are developed using nonlinear time-history analysis in terms of the peak curvature of pier column and displacement of bearings. Finally, the system fragility curves were derived by implementing Monte Carlo simulation on multinormal distribution of two components. The results from component and system fragilities reveal that the influence of aftershocks appears to be harmful to bridges at four considered damage states in terms of increasing damage probability conditional on a specific PGA. Additionally, it is better to evaluate the vulnerability of bridge system, rather than only assess the effect of aftershock based on a single component.

\section{Conflicts of Interest}

The authors declare that they have no conflicts of interest.

\section{Acknowledgments}

This research is supported by the Fundamental Research Funds for the Central Universities, China University of Geosciences (Wuhan) under Grant no. G1323521673, China Postdoctoral Science Foundation under Grant no. 2016M592407, 

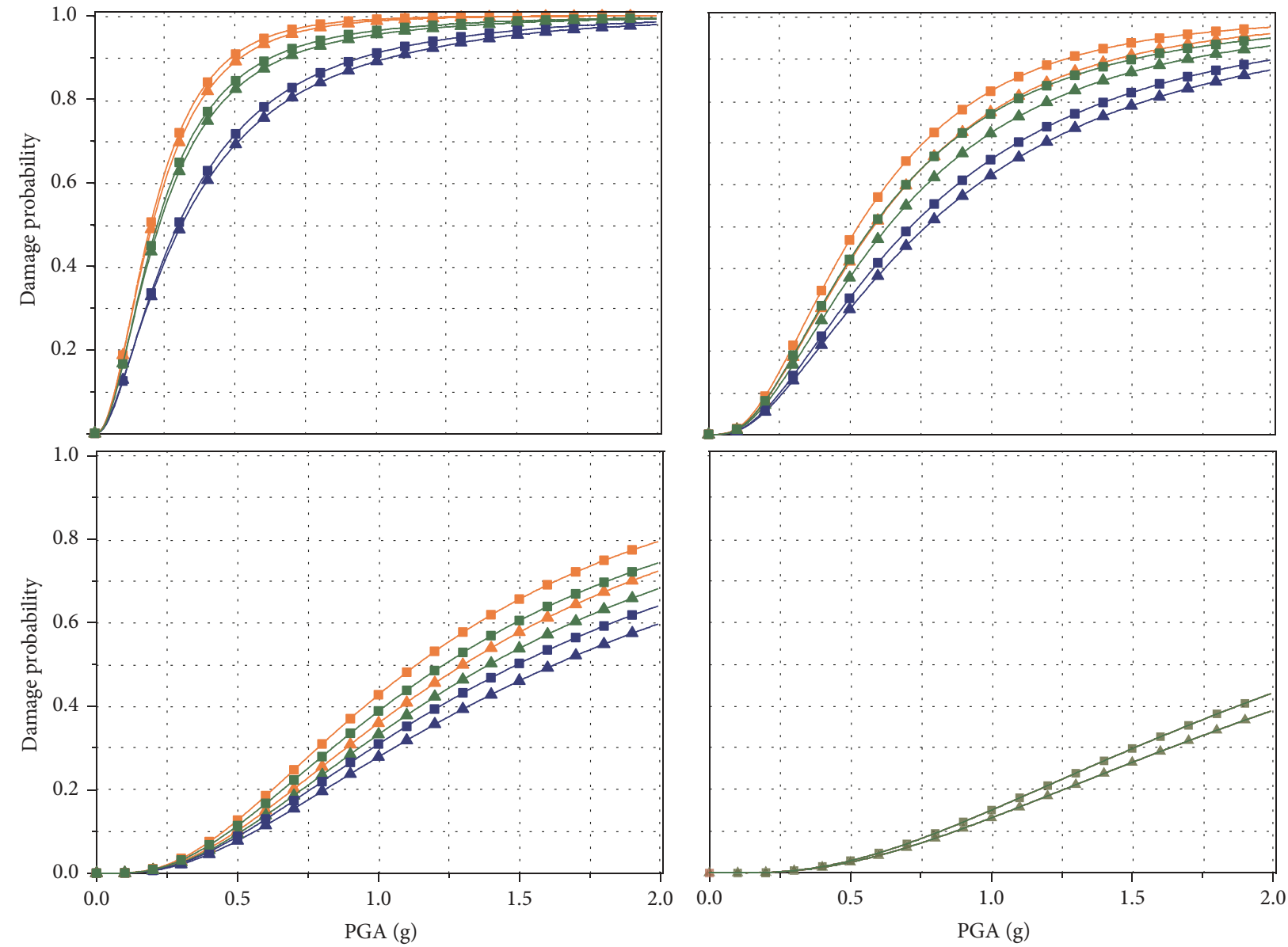

- Low bound, mainshock

$\rightarrow$ Low bound, MS-AS sequence

- Up bound, mainshock

- Low bound, mainshock

$\rightarrow$ Low bound, MS-AS sequence

$\rightarrow$ Up bound, mainshock

$\rightarrow$ Up bound, MS-AS sequence

- Bridge system, mainshock

- Bridge system, mainshock

- Bridge system, MS-AS sequence

FIGURE 7: System fragility curves of the considered bridge class under mainshock and MS-AS sequences.

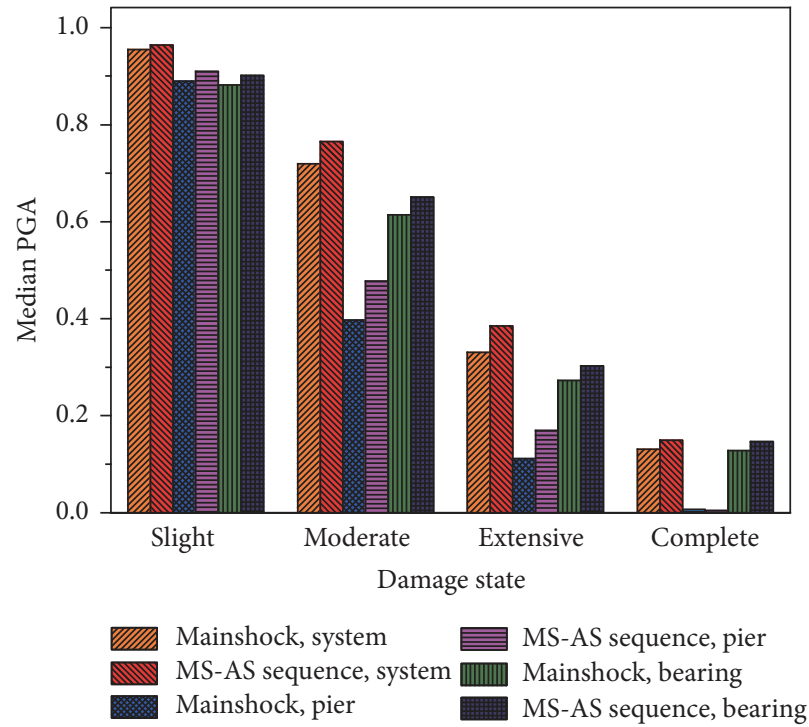

FIGURE 8: Comparison of median fragility for component and system fragility curves. 
and the National Natural Science Foundation of China under Grant no. 51708527.

\section{References}

[1] A. S. Elnashai, J. J. Bommer, and A. Martinez-Pereira, "Engineering Implications of Strong-motion Records From Recent Earthquakes," in Proceedings of the 11th European Conference on Earthquake Engineering, Paris, France, 1998.

[2] R. Shcherbakov, M. Nguyen, and M. Quigley, "Statistical analysis of the $2010 \mathrm{M}_{W} 7.1$ darfield earthquake aftershock sequence," New Zealand Journal of Geology and Geophysics, vol. 55, no. 3, pp. 305-311, 2012.

[3] K. Goda, A. Pomonis, S. C. Chian et al., "Ground motion characteristics and shaking damage of the 11th March 2011 Mw9.0 Great East Japan earthquake," Bulletin of Earthquake Engineering, vol. 11, no. 1, pp. 141-170, 2013.

[4] G. L. Yeo and C. A. Cornell, "A probabilistic framework for quantification of aftershock ground-motion hazard in California: Methodology and parametric study," Earthquake Engineering \& Structural Dynamics, vol. 38, no. 1, pp. 45-60, 2009.

[5] F. Jalayer, D. Asprone, A. Prota, and G. Manfredi, "A decision support system for post-earthquake reliability assessment of structures subjected to aftershocks: An application to L'Aquila earthquake," Bulletin of Earthquake Engineering, vol. 9, no. 4, pp. 997-1014, 2011.

[6] U. Gunasekaran, R. T. Amaladosson, P. Narayanan, and K. Ashokkumar, "Performance assessment of an existing reinforced cement concrete T-beam and slab bridge using pushover analysis," The Baltic Journal of Road and Bridge Engineering, vol. 8, no. 2, pp. 15-25, 2013.

[7] G. D. Hatzigeorgiou and D. E. Beskos, "Inelastic displacement ratios for SDOF structures subjected to repeated earthquakes," Engineering Structures, vol. 31, no. 11, pp. 2744-2755, 2009.

[8] K. Goda, "Nonlinear response potential of MainshockAftershock sequences from Japanese earthquakes," Bulletin of the Seismological Society of America, vol. 102, no. 5, pp. 2139-2156, 2012.

[9] K. Goda and C. A. Taylor, "Effects of aftershocks on peak ductility demand due to strong ground motion records from shallow crustal earthquakes," Earthquake Engineering \& Structural Dynamics, vol. 41, no. 15, pp. 2311-2330, 2012.

[10] R. Shcherbakov, D. L. Turcotte, and J. B. Rundle, "Aftershock statistics," Pure and Applied Geophysics, vol. 162, no. 6-7, pp. 1051-1076, 2005.

[11] J. Ruiz-García, "Mainshock-aftershock ground motion features and their influence in building's seismic response," Journal of Earthquake Engineering, vol. 16, no. 5, pp. 719-737, 2012.

[12] I. Iervolino, M. Giorgio, and E. Chioccarelli, "Closed-form aftershock reliability of damage-cumulating elastic-perfectlyplastic systems," Earthquake Engineering \& Structural Dynamics, vol. 43, no. 4, pp. 613-625, 2013.

[13] C.-H. Zhai, W.-P. Wen, Z. Chen, S. Li, and L.-L. Xie, "Damage spectra for the mainshock-aftershock sequence-type ground motions," Soil Dynamics and Earthquake Engineering, vol. 45, pp. 1-12, 2013.

[14] C. A. Cornell, F. Jalayer, R. O. Hamburger, and D. A. Foutch, "Probabilistic basis for 2000 SAC federal emergency management agency steel moment frame guidelines," Journal of Structural Engineering, vol. 128, no. 4, pp. 526-533, 2002.

[15] M. Shinozuka, M. Q. Feng, J. Lee, and T. Naganuma, "Statistical analysis of fragility curves," Journal of Engineering Mechanics, vol. 126, no. 12, pp. 1224-1231, 2000.
[16] Q. Li and B. R. Ellingwood, "Performance evaluation and damage assessment of steel frame buildings under main shockaftershock earthquake sequences," Earthquake Engineering \& Structural Dynamics, vol. 36, no. 3, pp. 405-427, 2007.

[17] N. Luco, P. Bazzurro, and C. A. Cornell, "Dynamic versus static computation of the residual capacity of a mainshockdamaged building to withstand an aftershock," in Proceedings of the 13th World Conference on Earthquake Engineering, p. 2405, Vancouver, Canada, 2004.

[18] H. Ryu, N. Luco, S. R. Uma, and A. B. Liel, "Developing fragilities for mainshock-damaged structures through incremental dynamic analysis," in Proceedings of the 9th Pacific Conference on Earthquake Engineering, paper no. 225, p. 225, Auckland, New Zealand.

[19] S. Muthukumar, A Contact Element Approach with Hysteresis Damping for the Analysis and Design of Pounding in Bridges, Georgia Institute of Technology, 2003.

[20] D. Beben, "Numerical analysis of a soil-steel bridge structure," The Baltic Journal of Road and Bridge Engineering, vol. 4, no. 1, pp. 13-21, 2009.

[21] K.-B. Han, S.-N. Hong, and S.-K. Park, "Seismic performance evaluation of retrofitted bridge by isolation bearings," The Baltic Journal of Road and Bridge Engineering, vol. 4, no. 3, pp. 134-142, 2009.

[22] Y.-J. Park and A. H.-S. Ang, "Mechanistic seismic damage model for reinforced concrete," Journal of Structural Engineering, vol. 111, no. 4, pp. 722-739, 1985.

[23] J. B. Mander and C. T. Cheng, "Renewable Hinge Detailing for Bridge Columns," in Pacific Conference on Earthquake Engineering, Parkville, Australia, 1995.

[24] A. El-Bahy, S. K. Kunnath, W. C. Stone, and A. W. Taylor, "Cumulative seismic damage of circular bridge columns: benchmark and low-cycle fatigue tests," ACI Structural Journal, vol. 96, no. 4, pp. 633-641, 1999.

[25] A. El-Bahy, S. K. Kunnath, W. C. Stone, and A. W. Taylor, "Cumulative seismic damage of circular bridge columns: variable amplitude tests," ACI Structural Journal, vol. 96, no. 5, pp. 711-719, 1999.

[26] R. Kumar, P. Gardoni, and M. Sanchez-Silva, "Effect of cumulative seismic damage and corrosion on the life-cycle cost of reinforced concrete bridges," Earthquake Engineering \& Structural Dynamics, vol. 38, no. 7, pp. 887-905, 2009.

[27] U. Patxi, Towards Earthquake Resistant Design of Concentrically Braced Steel Structures, University of California, Berkeley, Calif, USA, 2005.

[28] B. G. Nielson and R. DesRoches, "Seismic fragility methodology for highway bridges using a component level approach," Earthquake Engineering \& Structural Dynamics, vol. 36, no. 6, pp. 823-839, 2007.

[29] Y. Pang, X. Wu, G. Shen, and W. Yuan, "Seismic fragility analysis of cable-stayed bridges considering different sources of uncertainties," Journal of Bridge Engineering, vol. 19, no. 4, Article ID 04013015, 2014.

[30] J. E. Padgett, B. G. Nielson, and R. DesRoches, "Selection of optimal intensity measures in probabilistic seismic demand models of highway bridge portfolios," Earthquake Engineering \& Structural Dynamics, vol. 37, no. 5, pp. 711-725, 2008.

[31] J. E. Padgett and R. DesRoches, "Methodology for the development of analytical fragility curves for retrofitted bridges," Earthquake Engineering \& Structural Dynamics, vol. 37, no. 8, pp. 1157-1174, 2008. 


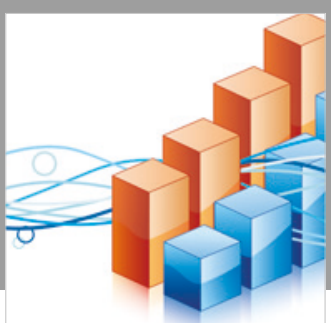

Advances in

Operations Research

\section{-n-m}
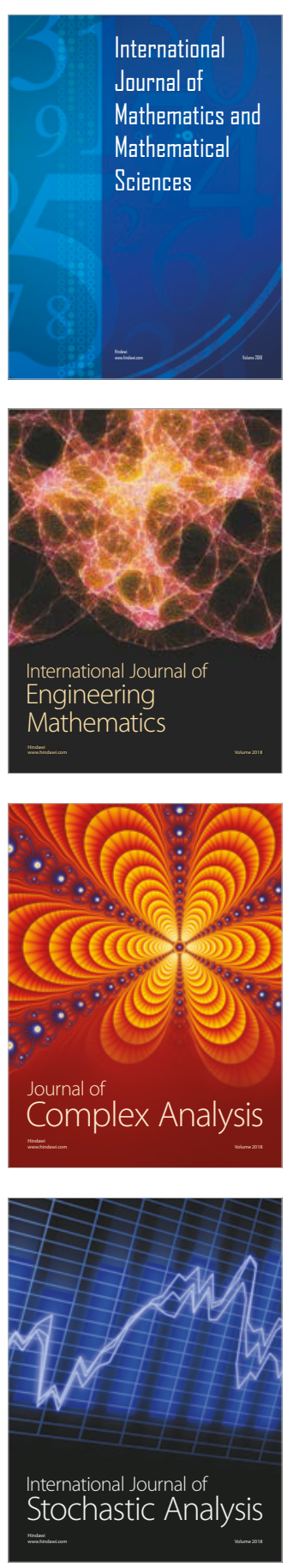
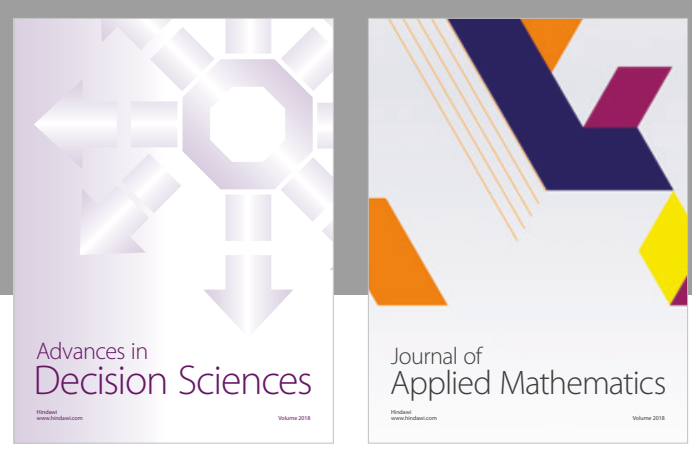

Journal of

Applied Mathematics
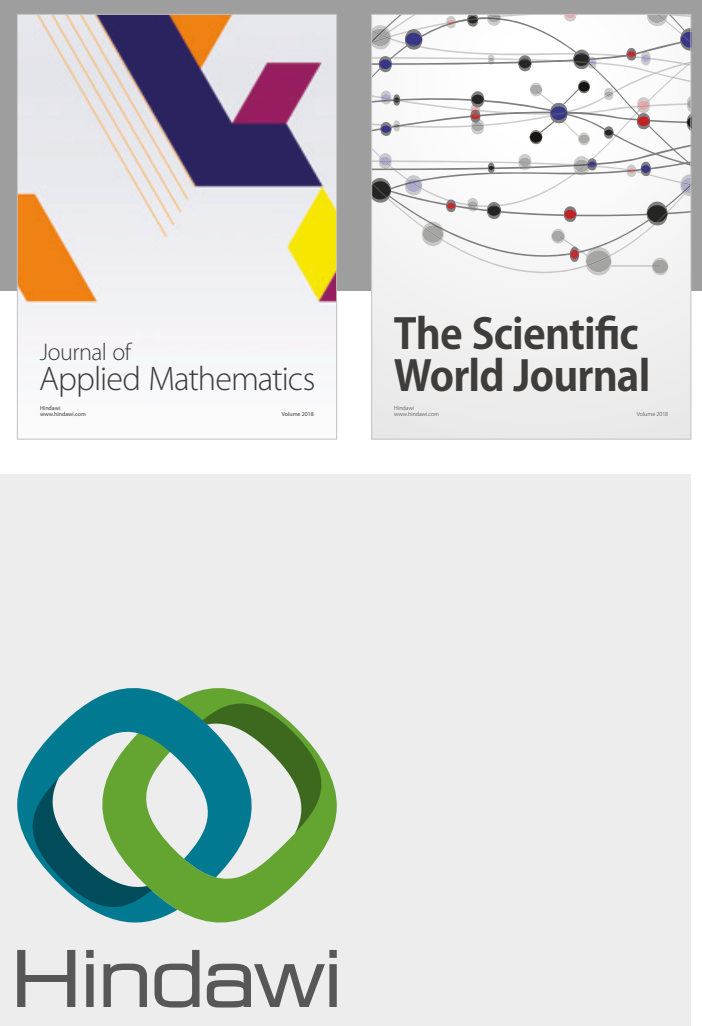

Submit your manuscripts at

www.hindawi.com

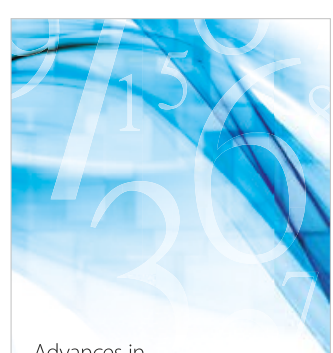

Advances in
Numerical Analysis
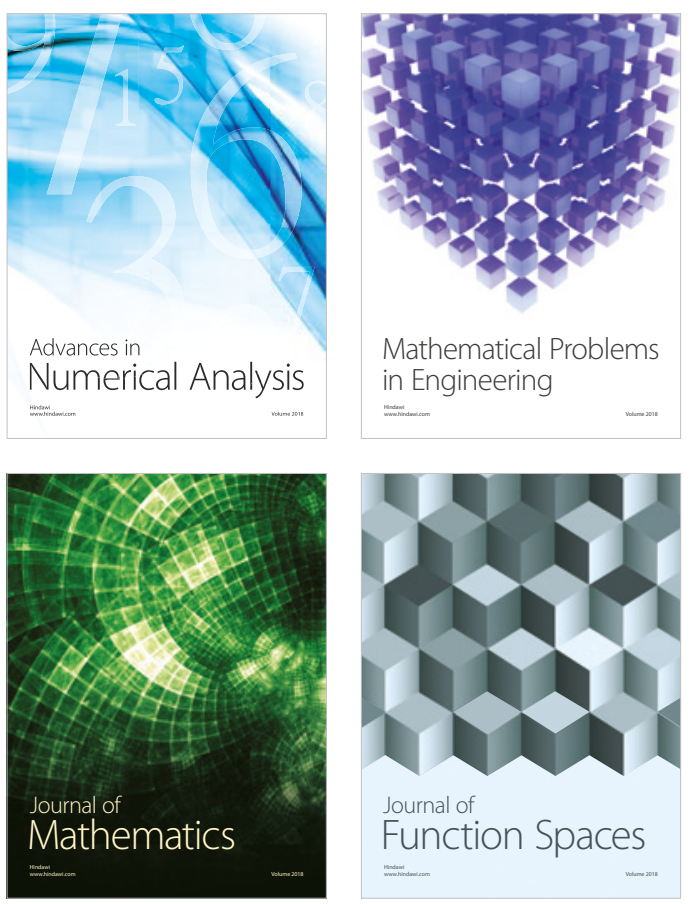

Mathematical Problems in Engineering

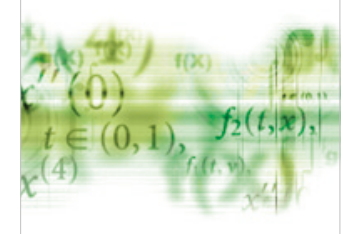

International Journal of

Differential Equations

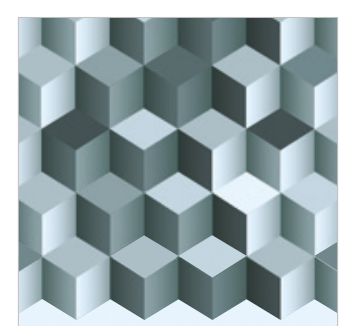

Journal of

Function Spaces

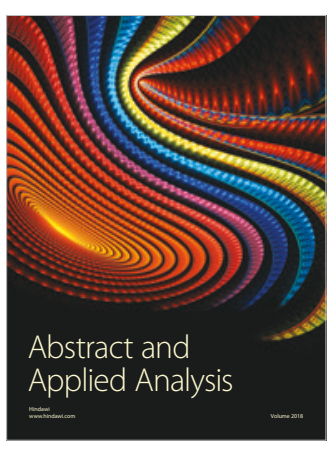

The Scientific

World Journal

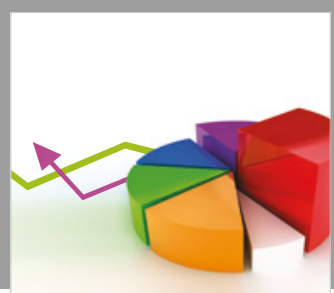

Journal of

Probability and Statistics
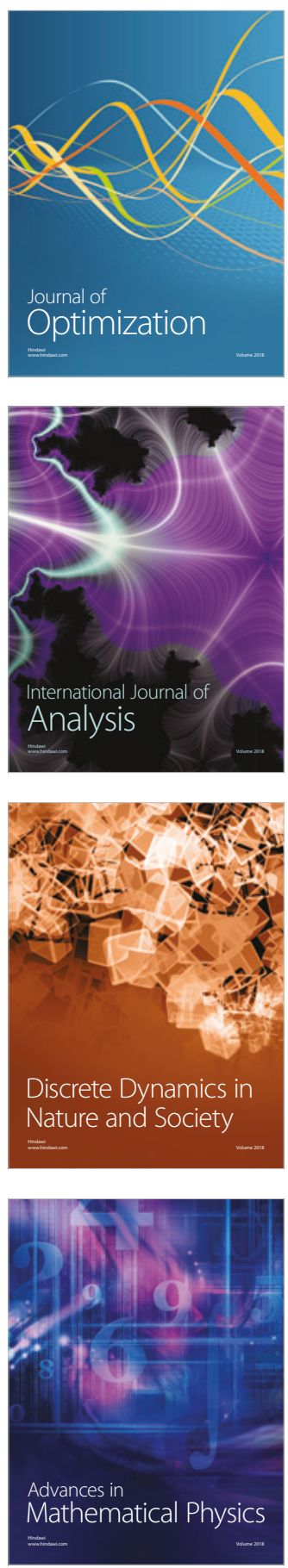